\title{
THE APRIL MEETING IN MONTEREY
}

The five hundred ninety-first meeting of the American Mathematical Society was held on Saturday, April 29, 1962 at the U. S. Naval Postgraduate School, in Monterey, California. There were 142 registrants at this meeting, 119 of whom were members of the Society.

By invitation of the Committee to Select Hour Speakers for Far Western Sectional Meetings, Professor R. A. Beaumont of the University of Washington addressed the Society on Torsion free rings. He was introduced by Professor L. J. Paige.

There were five sessions for contributed papers with Professors R. G. Bartle, H. S. Bear, A. H. Cayford, S. P. Hughart, and E. J. Stewart presiding.

R. S. Pierce

Associate Secretary

Berkeley, California 